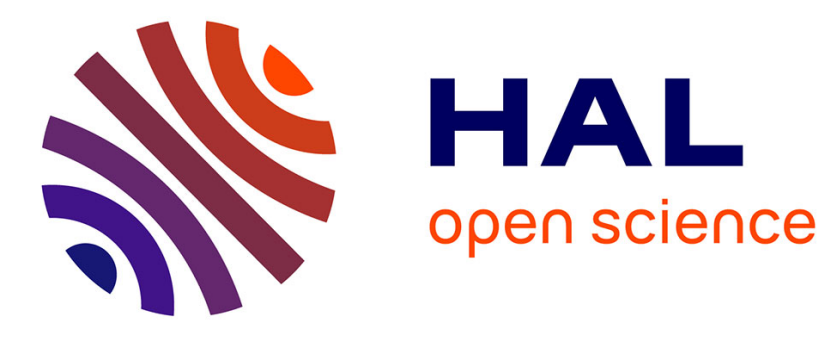

\title{
infection in primary care investigated by real-time PCR in England and Wales
}

\author{
V. J. Chalker, T. Stocki, M. Mentasti, D. Fleming, C. Sadler, J. Ellis, A. \\ Bermingham, T. G. Harrison
}

\section{- To cite this version:}

V. J. Chalker, T. Stocki, M. Mentasti, D. Fleming, C. Sadler, et al.. infection in primary care investigated by real-time PCR in England and Wales. European Journal of Clinical Microbiology and Infectious Diseases, 2011, 30 (7), pp.915-921. 10.1007/s10096-011-1176-3 . hal-00669194

\section{HAL Id: hal-00669194 \\ https://hal.science/hal-00669194}

Submitted on 12 Feb 2012

HAL is a multi-disciplinary open access archive for the deposit and dissemination of scientific research documents, whether they are published or not. The documents may come from teaching and research institutions in France or abroad, or from public or private research centers.
L'archive ouverte pluridisciplinaire HAL, est destinée au dépôt et à la diffusion de documents scientifiques de niveau recherche, publiés ou non, émanant des établissements d'enseignement et de recherche français ou étrangers, des laboratoires publics ou privés. 

in England and Wales.

$4 \quad$ Bermingham $^{1}$ and T. G. Harrison ${ }^{1}$

Running title: Mycoplasma pneumoniae PCR, epidemiology.

6

*Author for correspondence: e-mail vicki.chalker@hpa.org.uk Tel: +44 2083276776.

8 Fax: +442082056528.

${ }^{1}$ Respiratory and Systemic Infection Laboratory, Health Protection Agency Centre for 10 Infections. 61 Colindale Avenue, London NW9 5EQ, UK. ${ }^{2}$ Birmingham Research Unit of the Royal College of General Practitioners, Birmingham, 12 BD17 9DB, UK. 
Abstract

Real-time PCR was employed to detect a conserved region of the P1 cytadhesin gene of Mycoplasma pneumoniae in combined nose and throat swabs collected from patients attending GP surgeries during 2005-2009 with symptoms of respiratory tract infection (RTI). Samples were collected as part of an annual winter epidemiological and virological linked study in England and Wales. A total of 3987 samples were tested, $65(1.7 \%, 95 \% \mathrm{Cl} 1.3-2.1)$ had detectable $\mathrm{M}$. pneumoniae DNA. Positive patients were detected of both sex, aged from 9 months to 78 years, had clinical signs of upper RTI, fever and/or myalgia, influenza like illness to lower RTI. Mixed infections were identified in four cases, two with influenza A H1, one with H3 and one with influenza B. Children aged 5-14 years were more likely to have detectable $M$. pneumoniae in samples than all other age groups (Fishers $p=0.03$ ), attributed to the 2005-2006 season in which $6.0 \%(12 / 200,95 \% \mathrm{Cl} 3.4-10.3)$ of $5-14$ year olds had detectable $M$. pneumoniae in comparison to $2.2 \%$ in $2006-2007(3 / 14195 \% \mathrm{Cl} 0.5-6.4), 2.2 \%$ in $2007-2008(2 / 89$ $95 \% \mathrm{Cl} 0.1-8.3)$ and $0 \%$ in $2008-2009(0 / 15195 \% \mathrm{Cl} \mathrm{0-2.9).}$ 
Mycoplasma pneumoniae is a common cause of community-acquired pneumonia (CAP) transmitted by aerosol or close contact. Major increases and decreases in M.pneumoniae infection have occurred periodically in the UK and severity of clinical symptoms range from asymptomatic to pronounced pneumonia [2]. Mycoplasma pneumoniae is found in all age groups however it is one of the most common etiological agents of CAP found in children with pneumonia over 5 years old [1]. Admissions to a UK hospital in patients with CAP that were attributable to $M$. pneumoniae were estimated at 18\% in 1982 and 4\% in 1999 [11]. Historically within the UK M. pneumoniae epidemics have occurred at approximately four yearly intervals and have lasted 12 to 15 months, concurrent with sporadic infection at a lower level (Fig. 1). In England and Wales data from voluntary laboratory reports are collated by the Health Protection Agency Centre for Infections (HPA) to give a representative indication of the number of patients testing positive for M. pneumoniae per week, (Fig. 1). Data on patients testing negative is not available and because reporting is voluntary is it not known whether the data reported is a true representation of the number of positive cases in England and Wales. Furthermore, since 1999 the number of voluntary reports received has decreased and the reducing incidence of $M$. pneumoniae has mirrored the reduction in incidence of respiratory tract infections and consequent reduced antibiotic prescribing in England and Wales, leading to a need for a more robust surveillance system for respiratory infections (Fig. 1) [7, 8]. Nucleic acid based surveillance screening has been used at the HPA and Royal College of General Practitioners Birmingham Research Unit for a number of years examining annual epidemics in England and Wales of influenza, respiratory syncytial virus (RSV) and human metapneumovirus in symptomatic patients attending sentinel general practitioners surgeries with respiratory symptoms (http://www.rcgp.org.uk/bru /bru home.aspx). The England and Wales respiratory viral screening programme during 2005 to 2009 was extended to include the detection of $M$. pneumoniae by real-time polymerase chain reaction (PCR) amplifying the P1 cytadhesin gene [17]. Data was collated regarding date of sampling, date of onset of respiratory 
symptoms, respiratory symptoms, age, sex, geographical location, M. pneumoniae detection and mixed infections with respiratory viruses. To give an indication of carriage in the community this method was also used to detect M. pneumoniae in 428 individuals in households in Hertfordshire, UK. Ethical approval was obtained.

\section{Materials and methods}

\section{Clinical samples - symptomatic patients}

A total of 3987 anonymised combined nose and throat swabs were taken from patients attending GPs during the winter months (weeks $~ 35-20$ ) of 2005-2009 as part of the annual viral epidemiological screen. All age groups were included except during the 2008-2009 period which included only children less than 15 years old. Samples were taken from patients (mean age 33.2, $S D \pm 21.3$, range 0 to 99 years) with clinical symptoms in the following categories, upper respiratory tract infection (URTI, sore throat, runny nose \pm otitis media); lower respiratory tract infection (LRTI, cough, dyspnoea, acute bronchitis, bronchitis or pneumonia); constitutional infection (fever, myalgia); influenza like illness (fever, myalgia and cough with duration of $<5$ days). A complete record of age, sex, onset and clinical signs was not available for every patient and antibiotic use prior to presentation was not known. Nucleic acid was extracted from the samples using the Roche MagNAPure robot using DNA isolation kit III (Roche Diagnostics) according to the manufacturers instructions and examined for evidence of respiratory viruses as described previously $[5,18]$. Total nucleic acid extracts were stored at $-80^{\circ} \mathrm{C}$ prior to testing for M. pneumoniae DNA by real-time PCR [17].

\section{Clinical samples - community subjects}

Subjects asymptomatic for respiratory infections during the same time period as above were not available for testing. Nasopharyngeal swabs were collected from 428 individuals from Hertfordshire, England in October 2001 as part of a study on pneumococcal carriage in healthy children and their families [12]. These samples were included in this study to ascertain the level of $M$. pneumoniae in the community population. Participants included family households with pre-school children, their 
91 parents, grandparents and siblings and therefore sampling was biased towards 92 households with younger average age groups. DNA was extracted from swabs as 93 detailed above after microbiological culture plating for other pathogens and exclusion $94 \quad$ criteria have been previously described [12].

\section{$95 \quad$ Mycoplasma pneumoniae PCR LightCycler assay} Assays were carried out using a LightCycler ${ }^{\mathrm{TM}}$ (Roche, United Kingdom) to amplify both M. pneumoniae and an internal processing control that detects inhibitory samples, with detection of 10 copies or more of the $M$. pneumoniae target sequence in $5 \mu \mathrm{l}$ sample DNA [17]. Uracil-DNA glycosylase (Roche) was added to each reaction to eliminate carry over contamination [15]. Only $0.1 \%(4 / 4448,95 \% \mathrm{Cl} 0.01-0.5)$ of samples were inhibitory to the assay of which all were negative on repeat testing on $1 / 10$ dilutions [17]. Data was analysed using Roche LightCycler software version 3.5 and an estimation of detectable M. pneumoniae DNA was made in direct comparison to a positive standard curve.

\section{Statistical analysis}

All statistical analysis was performed with GraphPad Quickcalcs (http://www.graphpad.com/quickcalcs/index.cf) (GraphPad Software Inc.) or in Microsoft confidence intervals are included where relevant.

\section{Results}

Mycoplasma pneumoniae was detected in $1.7 \%(65 / 3987,95 \% \mathrm{Cl}, 1.3-2.1)$ samples from patients presenting to general practitioners with influenza like illness and $0.2 \%$ $(1 / 428,95 \% \mathrm{Cl} 0.01-1.5)$ community subjects. Symptomatic patients were more likely to have detectable M. pneumoniae DNA than community subjects (Fishers Exact test $\mathrm{p}=0.02$ ). Laboratory reports of M. pneumoniae to HPA Centre for Infections in England and Wales by date of report, 1990-2010, including serological, molecular and culture test results are shown (Fig. 1). Detailed results for all age groups and clinical signs are listed (Table 1). M. pneumoniae infection was detected in $41 / 2877(1.4 \%, 95 \% \mathrm{Cl} 0.8-2.2)$ 
symptomatic adult patients aged 15 years and older. Children aged 5 to 14 years presenting to general practitioners with evidence of respiratory infection were more likely to have detectable M. pneumoniae DNA than all other age groups $(3.0 \%, 17 / 564,95 \% \mathrm{Cl}$ 1.9-4.8, Fishers exact test $p=0.03$, Table 1, Fig. 2) irrespective of clinical signs. This was attributed to the $2005-2006$ season in which $6.0 \%(12 / 200,95 \% \mathrm{Cl} 3.4-10.3)$ of $5-14$ year olds sampled had detectable M. pneumoniae in comparison to $2.2 \%$ in $2006-2007$ (3/141 95\% Cl 0.5-6.4), 2.2\% in 2007-2008 (2/89 95\% Cl 0.1-8.3) and 0\% in 2008-2009 (0/151 95\% Cl 0-2.9). A significant number of positive cases in the $5-14$ year olds $(6.0 \%)$ in 2005-2006 was found when compared to all age groups in all years $(1.3 \%, 53 / 3787$, 95\% $\mathrm{Cl} 0.9-2.0$, Fishers exact test $\mathrm{p}=0.0001)$. A decreasing incidence trend was seen in all age groups from 2005 to 2009 excepting those under 5 years (Fig. 2). The 5 to 14 year old age group was less likely to have M. pneumoniae in the 2008-2009 season than other seasons $(0 / 151,0 \%, 95 \% \mathrm{Cl} 0-2.9$ vs $17 / 430,4.0 \%, 95 \% \mathrm{Cl} 2.4-6.3$ Fishers exact test $p=0.009$ ). Positive patients were on average 5 years younger than negative patients

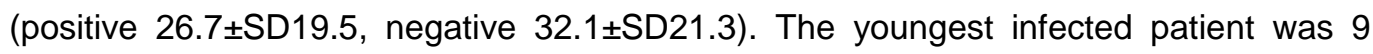
months old. All M. pneumoniae positive cases presented and were detected within 17 days of onset of symptoms (0-17 days, mean $5 \pm$ SD3.8), whereas negative patients presented up to 87 days post onset (0-87 days, mean $5 \pm$ SD6.3).

In this study of patients presenting to GPs, those with LRT clinical signs only had higher M. pneumoniae loads $\left(1.1 \times 10^{4} \pm \mathrm{SD} 2.8 \times 10^{4}\right)$ than patients with URT clinical signs only $\left(4.4 \times 10^{3} \pm S D 7.3 \times 10^{3}\right)$ or patients with both URT and LRT clinical signs $\left(4.2 \times 10^{3} \pm S D 5.9 \times 10^{3}\right)$. The DNA load was also higher in patients with fever, without LRT or URT $\left(9.8 \times 10^{3} \pm \operatorname{SD} 2.2 \times 10^{4}\right)$. Load data was normally distributed if log transformed for all categories. A statistical difference was not found in either comparison (using Student's t-test). No difference was found in age groups and DNA load of $M$. pneumoniae.

The number of $M$. pneumoniae positives cases per week is shown in addition to influenza virus, human metapneumonvirus (HMPV) and RSV (Fig. 3). Mixed infections were detected in $4 / 65(6.2 \%, 95 \% \mathrm{Cl} 1.9-15.2)$ symptomatic patients that were PCR 
positive for $M$. pneumoniae. One patient had $M$. pneumoniae and influenza $\mathrm{B}$, two $M$. pneumoniae and influenza A H1 and one M. pneumoniae and influenza A H3.

\section{Discussion}

The level of $M$. pneumoniae infection detected in symptomatic patients was low $(65 / 3987 ; 1.7 \% 95 \% \mathrm{Cl}, 1.3-2.1)$ and all age groups had detectable $M$. pneumoniae infection. The level of $M$. pneumoniae infection detected in symptomatic adult patients aged 15 years and older $(41 / 28771.4 \%, 95 \% \mathrm{Cl} 0.8-2.2)$ was similar to that found previously $(1.3 \%)$ in throat swabs, nasal aspirates and sputum from adult patients with LRTI attending GP clinics in London [3].

The higher childhood incidence in 5-14 year olds $(6.0 \%, 12 / 200,95 \% \mathrm{Cl} 3.4$ 10.3) noted in $2005-2006$ is consistent with a rise in national $M$. pneumoniae reports in the same period (Fig. 1) occurring four years following the previous epidemic period. This supports other studies in which children of school age present with higher infection rates with M. pneumoniae [19] and is consistent with the hypothesis that infection of children may drive epidemic cycles. The decreasing incidence trend seen in all age groups from 2005 to 2009 excepting those under 5 years (Fig. 2) was reflected by the observation that the 5 to 14 year old age group was less likely to have $M$. pneumoniae in the 2008-2009 season than other seasons. Conversely, in 2008-2009 an increase in the under 5 year age group was noted (Fig. 2), although not statistically significant in comparison to other age groups. The beginning of cycles of infection may start in the youngest age group or naive population. Natural immunity develops to $M$. pneumoniae with age and children may be more susceptible due to lack of previous exposure. However, immunity may be transitory and recurrent isolation and serological responses have been found [6] and persistent infections have been noted [9]. Younger children and infants have an increased severity of clinical signs when infected with $M$. pneumoniae in comparison to older children [19], again perhaps reflecting lack of previous exposure. Positive patients were on average 5 years younger than negative patients reinforcing $M$. pneumoniae as an infection more common in younger patients. 
Kleemola et al. [13] found that 3 weeks after PCR confirmed infection during an outbreak of $M$. pneumoniae $93 \%$ of cases were negative by PCR, indicating clearance of detectable organisms occurs in under 21 days in most individuals. In this study all $M$. pneumoniae positive cases were detected within 17 days, however follow-up samples were not available to ascertain clearance of infection.

In this study the youngest infected patient was 9 months old. Defilippi et al. [4] recently reported infection in infants of only 1 month old and noted that children less than 5 years old had a differing clinical presentation to older children (tachypnoea, upper respiratory tract involvement, diarrhoea and vomiting were more common) and are more likely to have concurrent RSV infection [4]. By comparing observed peaks of infected individuals (Fig. 3) M. pneumoniae infection seems to run concurrently with RSV rather than with influenza annual peaks, however, specific association has not been made. Mixed infections were detected in symptomatic patients that were PCR positive for $M$. pneumoniae with influenza $\mathrm{B}$, influenza $\mathrm{A} \mathrm{H} 1$ or influenza $\mathrm{A} \mathrm{H} 3$. Similar to this study mixed infections have been documented in a region of France in nasal swabs [14] in which mixed infections of $M$. pneumoniae with RSV, influenza A and B were recorded each year and $M$. pneumoniae was found to be the second most prevalent pathogen under test (to influenza A). Over a five year period M. pneumoniae detection in a region of France varied from $2.0 \%$ to $10.1 \%$, proposed to be attributed to epidemic and sporadic circulating strains. In our study detection rates were lower per annum (0.9 to $3.0 \%$ ), perhaps reflecting a sporadic circulation of strains as opposed to an epidemic year due to a strain of $M$. pneumoniae.

Symptomatic patients were only examined during September to April in this study and therefore the annual rate cannot be calculated and seasonal differences cannot be inferred.

Recently Nilsson et al. [16] demonstrated that oropharyngeal secretions from hospitalized patients contained higher detectable loads of $M$. pneumoniae than outpatients. In this study of patients presenting to GPs, those with LRT clinical signs had higher loads than patients with URT clinical signs or patients with both URT and LRT 
clinical signs. The DNA load was also higher in patients with fever, without LRT or URT, although a statistical difference was not found in either comparison.

Asymptomatic carriage has been reported to occur within the community and up to $13 \%$ of healthy adults may act as carriers of $M$. pneumoniae during epidemic periods $[9,10]$. In total $1.7 \%(65 / 3987,95 \% \mathrm{Cl}, 1.3-2.1)$ samples from patients presenting to general practitioners with influenza like illness and $0.2 \%(1 / 428,95 \% \mathrm{Cl} 0.01-1.5)$ community subjects were positive by PCR, giving an indication of the level of carriage of interesting to determine the level of carriage in asymptomatic patients with $M$. pneumoniae in the population during a $M$. pneumoniae epidemic period, however such samples were not available in this study. Symptomatic patients were more likely to have detectable M. pneumoniae DNA than community subjects (Fishers Exact test $\mathrm{p}=0.02$ ). The length of colonisation in asymptomatic individuals, the rate of transmission to others and the proportion that go on to develop clinical signs of $M$. pneumoniae infection remains unknown.

Focussing epidemiological studies on children only may result in the detection of outbreaks and individuals most susceptible to severe infection whilst decreasing the costs of large scale screening. Defilippi et al. [4] found that as many as $11 \%$ of children hospitalised with lower respiratory signs have M. pneumoniae detectable by PCR. This fact, combined with the data shown here which indicate that 1 in every 15 children aged 5-14 in winter 2005/06 attending general practitioners with clinical respiratory signs had detectable $M$ pneumoniae in a non-invasive sample signifies that an increase in testing of children may be beneficial. This study establishes the feasibility of mass screening for Mycoplasma pneumoniae detection that can help inform GPs and hospital clinicians particularly paediatricians of likely epidemic years.

To conclude, this study describes detection of M. pneumoniae infection by PCR in England and Wales linked to a well established virological surveillance programmes. Overall M. pneumoniae was detected in $1.7 \%$ patients presenting to GPs with respiratory symptoms/influenza-like illness and in $0.2 \%$ community subjects. Mixed 

cases. In 2005-2006 6.0\% 5-14 year olds presenting to GPs with respiratory symptoms/influenza-like illness had detectable M. pneumoniae infection.

The Authors would like to thank the Birmingham Research Unit of the Royal College of General Practitioners, the HPA Surveillance of Influenza Group, CDSC HPA for Fig. 1, carriage data.

244 
1. BTS Guidelines for the Management of Community Acquired Pneumonia in Childhood (2002) Thorax 57:1-24

2. Clyde WA (1993) Clinical Overview of typical M. pneumoniae infections. Clin Infect Dis 17 [Suppl]3:S32-36

3. Creer DD, Dilworth JP, Gillespie SH, Johnston AR, Johnston SL, Ling C, Patel S, Sanderson G, Wallace PG, McHugh TD (2006) Aetiological role of viral and bacterial infections in acute adult lower respiratory tract infection (LRTI) in primary care. Thorax. 61:75-79

4. Defilippi A, Silvestri M, Tacchella A, Giacchino R, Melioli G, Di Marco E, Cirillo C, Di Pietro P, Rossi GA (2008) Epidemiology and clinical features of Mycoplasma pneumoniae infection in children. Respir Med 102:1762-1768

5. Ellis JS, Fleming DM, Zambon MC (1997) Multiplex reverse transcription -PCR for surveillance of Influenza A and B viruses in England and Wales in 1995 and 1996. J Clin Microbiol 35:2076-2082

6. Ferwerda A, Moll HA, de Groot R (2001) Respiratory tract infections by Mycoplasma pneumoniae in children: a review of diagnostic and therapeutic measures. Eur $\mathrm{J}$ Pediatr 160:483-491

7. Fleming DM, Ross AM, Cross KW, Kendall H (2003) The reducing incidence of respiratory tract infection and its relation to antibiotic prescribing. $\mathrm{Br} \mathrm{J}$ Gen Pract $53: 778-783$

8. Fleming DM, Elliot AJ (2008) Lessons from 40 years' surveillance of influenza in England and Wales. Epidemiol Infect 136:866-875

9. Foy HM (1993) Infections caused by M. pneumoniae and possible carrier state in different populations of patients. Clin Infect Dis 17 [Suppl]1:S37-46

10. Gnarpe J, Lundback A, Sundelof B, Gnarpe H (1992) Prevalence of M. pneumoniae in subjectively healthy individuals. Scand J Infect Dis 24:161-164 
11. Howard LS, Sillis M, Pasteur MC, Kamath AV, Harrison BD (2005) Microbiological profile of community-acquired pneumonia in adults over the last 20 years. J Infect 50:107-113

275

276

277

278

279

280

281

282

283

284

285

286

287

288

289

290

291

292

293

294

295

296

297

298

299

12. Hussain M, Melegaro A, Pebody RG, George R, Edmunds WJ, Talukdar R, Martin SA, Efstratiou A, Miller E (2005) A longitudinal household study of S. pneumoniae nasopharyngeal carriage in a UK setting. Epidemiol Infect 133:891-898

13. Kleemola M, Jokinen C (1992) Outbreak of M. pneumoniae infection among hospital personnel studied by a nucleic acid hybridization test. J Hosp Infect 21:213-221

14. Layani-Milon MP, Gras I, Valette M, Luciani J, Stagnara J, Aymard M, Lina B (1999) Incidence of upper respiratory tract Mycoplasma pneumoniae infections among outpatients in Rhône-Alpes, France, during five successive winter periods. J Clin Microbiol 37:1721-1726

15. Longo MC, Berninger MS, Hartley JL (1990) Use of uracil DNA glycosylate to control carry-over in polymerase chain reaction. Gene 93:125-128

16. Nilsson AC, Björkman P, Welinder-Olsson C, Widell A, Persson K (2010) Clinical severity of Mycoplasma pneumoniae (MP) infection is associated with bacterial load in oropharyngeal secretions but not with MP genotype. BMC Infect Dis 25:10-39

17. Pitcher D, Chalker VJ, Sheppard C, George RC, Harrison TG (2006) Real-time detection of $M$. pneumoniae in respiratory samples with an internal processing control. J Med Microbiol 55:149-155

18. Stephenson I, Democratis J, Lackenby A, McNally T, Smith J, Pareek M, Ellis J, Bermingham A, Nicholson K, Zambon M (2009) Neuraminidase resistance after oseltamivir treatment of acute influenza A and B in children. Clin Infect Dis 48:389396

19. Vervloet LA, Marguet C, Camargos PA (2007) Infection by Mycoplasma pneumoniae and its importance as an etiological agent in childhood community-acquired pneumonias. Braz J Infect Dis 11:507-514 
Fig. 1.

302 Laboratory reports of M. pneumoniae to HPA Centre for Infections in England and Wales

303 by date of report (1990-2010) including serological molecular and culture test results

304

305 Fig. 2.

306

Percentage positive M. pneumoniae patients per year and age (error bars indicate $95 \%$ confidence intervals) During 2008-2009 only children less than 15 years old were

308 included in the study

309

Fig. 3.

310

Percentage positive M. pneumoniae and respiratory virus patients per week $2005-39$ to

311 2009-07 (dotted error bars indicate 95\% confidence intervals) HMPV testing was only

312 performed in the 2007-2009 seasons

313

314 
315 Fig. 1. M. pneumoniae Laboratory reports to HPA Centre for Infections in England and Wales by

316 date of report, 1990-2010.



318 
Fig. 2. Percentage positive M. pneumoniae patients per week 2005-39 to 2009-07.

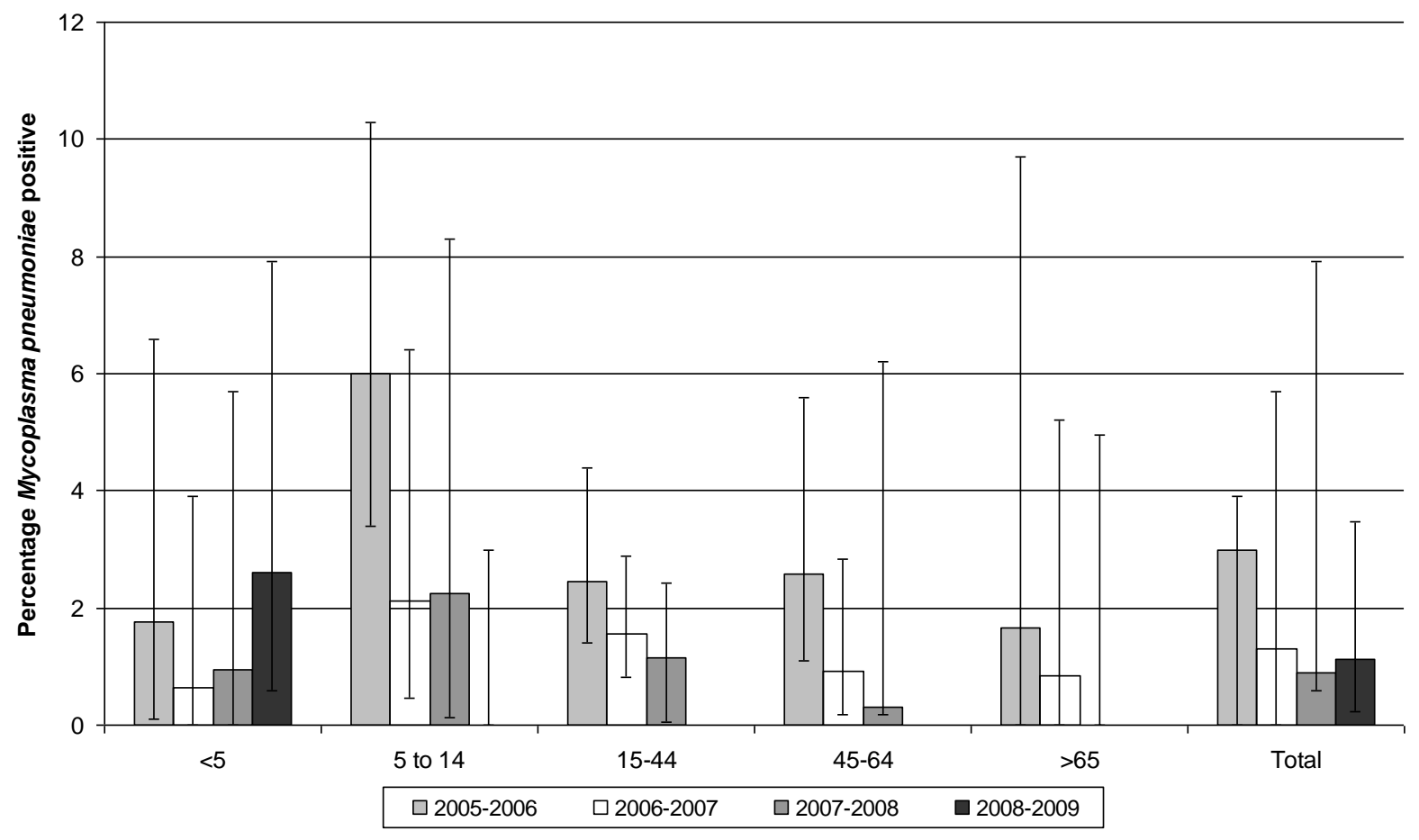

320 


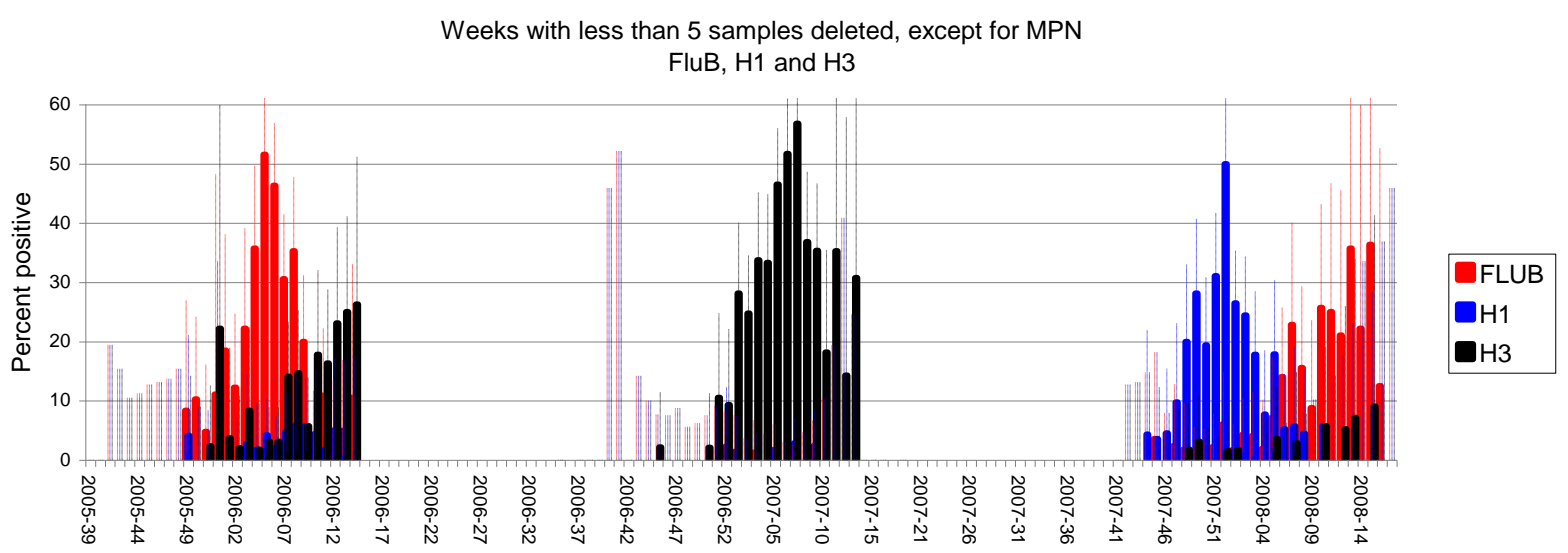

RSVA and RSVB



HMPV and Mycoplasma pneumoniae

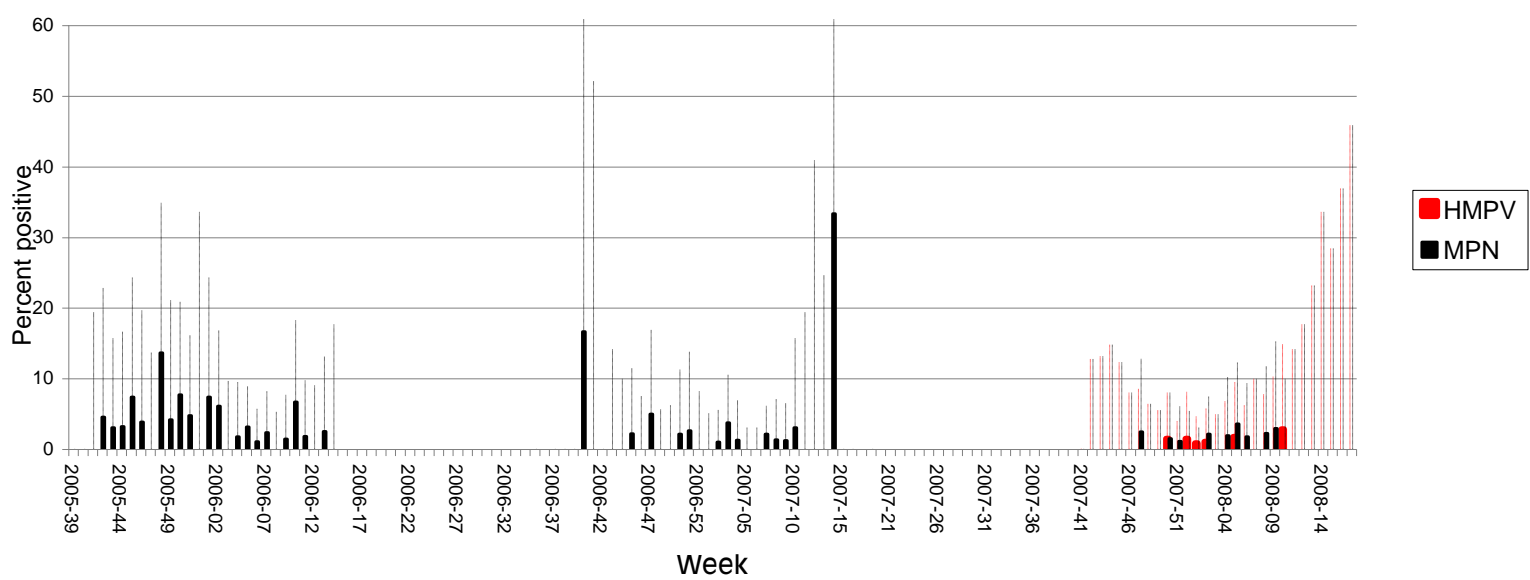


Table 1 Mycoplasma pneumoniae positive cases, sex, age, M. pneumoniae DNA load and clinical signs.

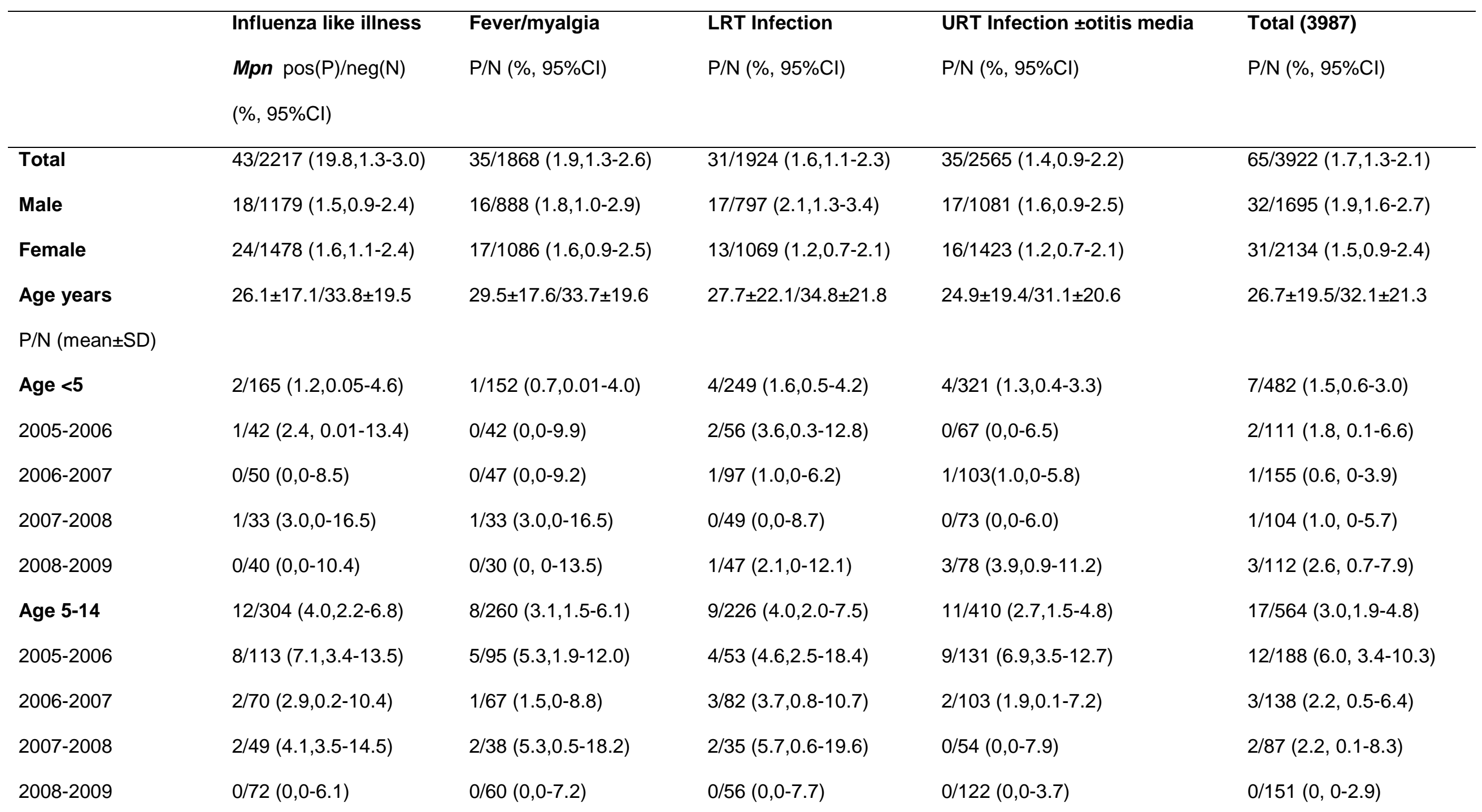




\begin{tabular}{|c|c|c|c|c|c|}
\hline Age 15-44 & 23/1072 (2.1,1.4-3.2) & $19 / 944(2 \cdot 0,1 \cdot 3-3.1)$ & $10 / 797(1.2,0.6-2.3)$ & $13 / 1146(1.1,0.6-1.9)$ & $29 / 1707(1.7,1.2-2.4)$ \\
\hline $2005-2006$ & $7 / 311(2.3,1.0-4.7)$ & $6 / 266(2.3,0.9-5.1)$ & $3 / 189(1.6,0.3-4.8)$ & $8 / 328(2.4,1.2-4.8)$ & $12 / 479(2.4,1.4-4.4)$ \\
\hline 2006-2007 & $10 / 385(2.6,1.4-4.5)$ & $9 / 346(2.6,1.3-4.9)$ & $4 / 375(1.1,0.3-2.8)$ & $4 / 426(0.9,0.3-2.5)$ & $10 / 630(1.6,0.8-2.9)$ \\
\hline 2007-2008 & $6 / 376(1.6,0.7-3.5)$ & 4/332 (1.2,0.4-3.2) & $3 / 233(1.3,0.3-3.9)$ & $1 / 392(0.3,0-1.6)$ & $7 / 598(1.2,0.05-2.4)$ \\
\hline Age 45-64 & $5 / 538(0.9,0.3-2.2)$ & $5 / 436(1.1,0.4-2.7)$ & $5 / 461(1.1,0.4-2.6)$ & $5 / 521(0.9,0.01-4.3)$ & $10 / 865(1.1,0.5-2.1)$ \\
\hline 2005-2006 & $5 / 142(3.5,1.3-8.2)$ & $4 / 123(3.3,1.0-8.3)$ & $4 / 101(4.0,1.2-10.7)$ & $2 / 141(1.4,0.06-5.4)$ & $6 / 227(2.6,1.1-5.6)$ \\
\hline 2006-2007 & $0 / 196(0,0-2.3)$ & $1 / 165(0.6,0-3.7)$ & $1 / 200(0.5,0-3.1)$ & 2/198 (1.0,0.04-3.9) & $3 / 322(0.9,0.2-2.8)$ \\
\hline 2007-2008 & $0 / 200(0,0-2.3)$ & $0 / 148(0,0-3.0)$ & $0 / 160(0,0-2.8)$ & $1 / 182(0.6,0-3.4)$ & $1 / 316(0.3,0.2-6.2)$ \\
\hline Age $>65$ & $0 / 111(0,0-4.0)$ & $1 / 106(0.9,0.01-5.6)$ & $2 / 172(1.2,0.1-4.4)$ & $1 / 142(0.7,0.01-4.3)$ & 2/264 (0.8,0.03-2.9) \\
\hline 2005-2006 & $0 / 32(0,0.12 .7)$ & $0 / 26(0,0-15.2)$ & $1 / 41(2.4,0-13.7)$ & $0 / 27(0,0-14.8)$ & $1 / 59(1.7,0-9.7)$ \\
\hline $2006-2007$ & $0 / 44(0,0.9 .6)$ & $1 / 44(2.3,0-12.9)$ & $1 / 74(0,0-8.0)$ & $1 / 63(1.6,0-9.3)$ & $1 / 116(0.9,0-5.2)$ \\
\hline 2007-2008 & $0 / 35(0,0-11.8)$ & $0 / 36(0,0-11.5)$ & $0 / 57(0,0-7.6)$ & $0 / 52(0,0-8.2)$ & $0 / 89(0,0-4.9)$ \\
\hline MPN DNA load & $7.7 \times 10^{3}\left(1.9 \times 10^{4}\right)$ & $9.0 \times 10^{3}\left(2.2 \times 10^{4}\right)$ & $7.4 \times 10^{3}\left(2.0 \times 10^{4}\right)$ & $4.3 \times 10^{3}\left(6.7 \times 10^{3}\right)$ & $6.8 \times 10^{3}\left(1.7 \times 10^{4}\right)$ \\
\hline Mean $( \pm S D)$, range & $2.6 \times 10^{1}-1.1 \times 10^{5}$ & $2.6 \times 10^{1}-1.1 \times 10^{5}$ & $1.4 \times 10^{2}-1.1 \times 10^{5}$ & $2.6 \times 10^{1}-3.1 \times 10^{4}$ & $2.6 \times 10^{1}-1.1 \times 10^{5}$ \\
\hline
\end{tabular}


325 